\begin{tabular}{|c|c|c|c|}
\hline & International Journal of Current Research in \\
Biosciences and Plant Biology & Volume 5 ・ Number 12 (December-2018) ・ ISSN: 2349-8080 (Online) \\
\hline EXCELLENT \\
PUBLISHERS
\end{tabular}

Review Article

doi: https://doi.org/10.20546/ijcrbp.2018.512.003

\title{
The Potential Effects of Vitamin E in Sport Performance
}

\section{Norhazira Abdul Rahim* and Nor Aijratul Asikin Mohamad Shalan}

\author{
Faculty of Sport Sciences and Coaching, Sultan Idris Education University, 35900, Tanjong Malim, \\ Perak, Malaysia
}

*Corresponding author.

\section{Article Info \\ Date of Acceptance: \\ 24 November 2018 \\ Date of Publication: \\ 06 December 2018}

\section{Keywords}

Antioxidants

Exercise

Oxidative stress

Sports performance

Supplementation

Vitamin E

\begin{abstract}
ABS TRA C T
In recent years, the consumption of antioxidants in athletes has markedly increased. Exercise and endurance activities require a large energy as well as cause a high turnover of antioxidant capacity through sweat losses, musculoskeletal repair process and metabolism in the body. Antioxidant system in the body becomes depleted during exercise which causes cells and tissues are more susceptible to reactive oxygen species (ROS). Antioxidants includes vitamin E have received attention predominantly as a nutritional strategy to maximize sport performance and preventing detrimental effects of ROS, which continuously generated during strenuous exercise. Vitamin E is a nonenzymatic and potent lipid-soluble antioxidants that able to scavenge and neutralize the ROS. Vitamin E has the ability to protect against oxidative stress in human and animal, as well as enhances physical endurance. Therefore, the aim of this review is to evaluate the potential effects of vitamin $\mathrm{E}$ in modulating oxidative stress in order to enhance physical performance in athletes. To date there is still poor evidence that dietary supplementation with vitamin E will improve sport performance. However it can be suggested that antioxidants supplementation rich in vitamin $\mathrm{E}$ may act as alternative strategy to improve physical performance.
\end{abstract}

\section{Introduction}

Recently antioxidant dietary and supplementation among athletes has become an interesting and controversial issue among researchers, coach and the athletes itself. Many athletes supplemented with antioxidants in belief this will help and improve the muscle damage, immune dysfunction and fatigue as well as to improve the performance, despite some evidence suggests it impairs training adaptations.
The recent review done by Pingitore et al. (2015), suggested that athletes' performance is related to training and physical adaptation and correct nutrition in individuals with specific genetic characteristics can facilitate such adjustments.

Reactive oxygen species (ROS) are produced within the body as a result of various physiological processes as well as pathological conditions. The positive correlation between the leakage of 
electrons in the mitochondria matrix from II and III complexes and the oxygen flux is the most wellknown hypothesis for explaining the ROS over generation against exercise (Sen, 2001). Apart from this, the activation of phospholipase A2 initiates a cascade of enzymes and thereby increasing reactive species (Sakellariou and Jackson, 2014).

Exercise, physical activities and sport are promoting the production of free radical in the working muscle. To protect against the exerciseinduce oxidative injury, muscle cells contain the complex of endogenous cellular mechanism (enzymatic and non-enzymatic antioxidants) to eliminate the free radical specifically the ROS. Furthermore the exogenous dietary antioxidants interacts with the endogenous antioxidants to form a cooperative network of cellular antioxidants (Powers et al., 2004).

Endurance athletes due to special circumstances, require an antioxidant system efficient than others; the system maintains normal function of the body and adjust to combat oxidative stress induced by free radicals(Adams and Best, 2002). Apart from the function to eliminate free radicals, many attempts have been made to reveal the physiological changes occur during exercise. Organ such as liver and heart as well as skeletal muscle help to remove lactate from the blood, however intense exercise can increase lactate production. Glycogen reserves are the source of energy in the liver and muscle, where their reduction during exercise can cause insufficient energy supply or oxygen to the muscles which leads to muscle fatigue.

Vitamin E is widely known as a powerful antioxidant to protect against oxidative stress. Oral administration of vitamin $\mathrm{E}$ isomer, tocotrienol-rich fragment (TRF) showed an increase of blood lactate and maintain the glycogen level, which resulted in enhancing the swimming capacity in rats (Lee et al., 2009). In addition, the current studies on vitamin $E$ not only limited to animal, but also have been investigated among human as well as trained athletes (Table 1). In this review, we aim to highlight the current findings on the effects of antioxidant supplementation rich in vitamin $\mathrm{E}$ on exercise and sport performance.

\section{Oxidative stress and exercise}

In general, oxidative stress is recognized to be involved in many physiological condition includes cellular aging (Makpol et al., 2010), neurodegenerative diseases and cancer (Valco et al., 2007). Oxidative stress occurs due to imbalance between oxidant production and the antioxidants capacity. Cells are protected against free radical and oxidants injury by a complex network of endogenous antioxidants. The measurement of the oxidative stress in vivo is difficult due to the complexity of the oxidant/ antioxidant network and the very short half-life of free radical. Lipid peroxidation is one of the contributors for production of free radicals and superoxide dismutase (SOD) has been identified as the first line of defense against them.

A good antioxidant status may be important in maintaining the healthy muscle function especially during recovery phase after acute exercise and endurance exercise activities. In response to endurance exercise, oxygen $\left(\mathrm{O}_{2}\right)$ consumption increases 10- to 20- fold systemically and as much as 100- to 200-fold at the level of the skeletal muscle (Halliwell and Gutteridge, 1999). Physiologic doses of exogenous antioxidants are required to maintain or re-establish redox homeostasis (Ratnam et al., 2006; Valco et al., 2007).

On the other hand, it was reported that the production of ROS in exercise act as signals that regulate molecular events which is important in cell adaptations to exercise in athletes. Free radical may act as a double-edges sword where they not only cause oxidative damage, but also up-regulate the expression of important enzyme that responsible for antioxidant defense. In fact, with exercise activity the plasma xanthine oxidase activity which involves in the generation of free radicals and activation of NF-kB in peripheral blood lymphocytes are increased after the marathon running (GomezCabrera et al., 2006). 
Table 1. List of the studies investigated the effect of vitamin E (single or combination) on physical and sport performance.

\begin{tabular}{|c|c|c|c|c|}
\hline References & $\begin{array}{l}\text { Vitamin } \mathbf{E} \\
\text { supplementation (doses } \\
\text { \& duration) }\end{array}$ & Subjects/ sample & Exercise protocol and test & $\begin{array}{l}\text { Finding (with vitamin } \mathbf{E} \\
\text { supplementation) }\end{array}$ \\
\hline Capó et al., 2016 & $\begin{array}{l}\text { Almonds and olive oil } \\
\text { enriched with ATF and } \\
\text { DHA; } 1 \text { month }\end{array}$ & $\begin{array}{l}\text { Human; } \\
\text { young and senior } \\
\text { athletes }\end{array}$ & $\begin{array}{l}\text { Maximal performance test; } \\
\text { Gene expression of antioxidant enzymes } \\
\text { (AE), blood polyphenol concentration }\end{array}$ & $\begin{array}{l}\uparrow \text { gene expression of } \mathrm{AE} \text { in } \\
\text { young; } \uparrow \text { blood polyphenol } \\
\text { concentration in senior athletes. }\end{array}$ \\
\hline Betik et al., 2016 & $\begin{array}{l}\text { TCT }+ \text { WPI ( single and } \\
\text { combination group; } 10 \\
\text { weeks }\end{array}$ & $\begin{array}{l}\text { Rats, 6-weeks old; } \\
\text { with high-fat diet }\end{array}$ & MT; 10 mins/2 times per week & $\begin{array}{l}\text { Both TCT and WPI groups ran } \\
\text { >longer }(2271 \pm 185 \mathrm{~m} \text { and } \\
2195 \pm 265 \mathrm{~m})\end{array}$ \\
\hline Sarir et al., 2015 & $\begin{array}{l}\text { VE succinate; } 60 \mathrm{mg} / \mathrm{kg} \\
\text { for } 6 \text { weeks; } 3 \text { hours } \\
\text { before exercise training }\end{array}$ & $\begin{array}{l}\text { Rats, } \\
\text { age 12-weeks old }\end{array}$ & $\begin{array}{l}\text { MT (with high intensity interval training); } \\
\text { serum protein levels of inflammatory } \\
\text { cytokines, IL- } 6 \text { and TNF- } \alpha\end{array}$ & $\downarrow$ IL-6; $\downarrow$ TNF- $\alpha$ \\
\hline Lee et al., 2009 & $\begin{array}{l}\mathrm{TRF}-25 \mathrm{mg} / \mathrm{kg} / \mathrm{ml} \\
\mathrm{TRF}-50 \mathrm{mg} / \mathrm{kg} / \mathrm{ml}\end{array}$ & $\begin{array}{l}\text { Rats, } \\
\text { age 6-weeks old }\end{array}$ & $\begin{array}{l}\text { Swimming endurance test ; swimming } \\
\text { time }\end{array}$ & $\begin{array}{l}\uparrow 268.0 \pm 24.1 \mathrm{mins}(\mathrm{TRF}-25) \\
\uparrow 332.5 \pm 24.3 \mathrm{~min} \\
p<0.05\end{array}$ \\
\hline Keong et al., 2006 & $\begin{array}{l}\text { TRF } 60 \text { mg/capsule; } 6 \\
\text { weeks }\end{array}$ & $\begin{array}{l}\text { Human, } \\
\text { Middle-age male with } \\
\text { heat-adapted }\end{array}$ & $\begin{array}{l}\text { MT; Total antioxidant status (TAS), lipid } \\
\text { peroxidation }\end{array}$ & $\begin{array}{l}\text { No improvement after } \\
\text { supplementation. }\end{array}$ \\
\hline Asha et al., 2003 & VE; 60 days & $\begin{array}{l}\text { Rats, } \\
\text { Young-, middle- old } \\
\text { age }\end{array}$ & $\begin{array}{l}\text { Swimming 30min/day; } \\
\text { Plasma lipid profile (HDL-C) }\end{array}$ & $\uparrow \mathrm{HDL}-\mathrm{C}$ in all age groups \\
\hline
\end{tabular}

$\alpha$-tocopherol, ATF; tocotrienol, TCT; whey proteins isolates, WPI; VE, vitamin E; TRF, tocotrienol-rich fraction; high-density lipoprotein cholesterol

(HDL-C), AE, antioxidant enzymes; motorized treadmill, MT; interleukin-6, IL-6; tumor necrosis factor alpha, TNF- $\alpha$. 
The repetition of aerobic training sessions in normoxia associated with resting exposure of hypoxia cause a decrease of plasma antioxidant which is probably enhanced by too low intakes of lipid-soluble antioxidants (Pialoux et al., 2009). On the other hand, the two oxidative stress markers; malondialdehydes (MDA) and plasma advanced oxidation protein product (AOPP) were found to increase in post-endurance training (Pialoux et al., 2009).

At this point, we can suggestthat exercise performance involves the interaction among both physiologic and biochemical as well as psychological factors. Many questions may rise on how body responses to exercise and sport performance from the level of cellular, molecular mechanism and the nutritional intake which may act as the primary contributor to human performance. Many studies have been done to elucidate the protective mechanism which important to identify the strategies to be applied by both endogenous and exogenous antioxidants in order to protect against ROS-mediated injury. Even though there are many findings indicate the potential effects of vitamin $\mathrm{E}$ supplementation in improving the health status and oxidative damage but the theoretical basis on how vitamin $\mathrm{E}$ may enhance performance is still remain unclear.

\section{Antioxidants, vitamin $\mathbf{E}$ and sport performance}

Recently the dietary supplementation appears as important role in an athlete's performance in order to gain an edge on the competition. The intake of supplemental antioxidants in athletes has increased enormously despite the unclear evidence of benefits.It has been shown that there was a correlation between the number of training session per week and antioxidants capacity.The increase production of free radicals with intense physical exercise may exceed the capacity of the antioxidant defense systems in the body and induce oxidative conditions (Fig. 1). Despite remarkable evidence of the benefits of various vitamins and supplements to maintain the balance between oxidative reactions and antioxidant equilibrium, controversial data are still observed in literatures.

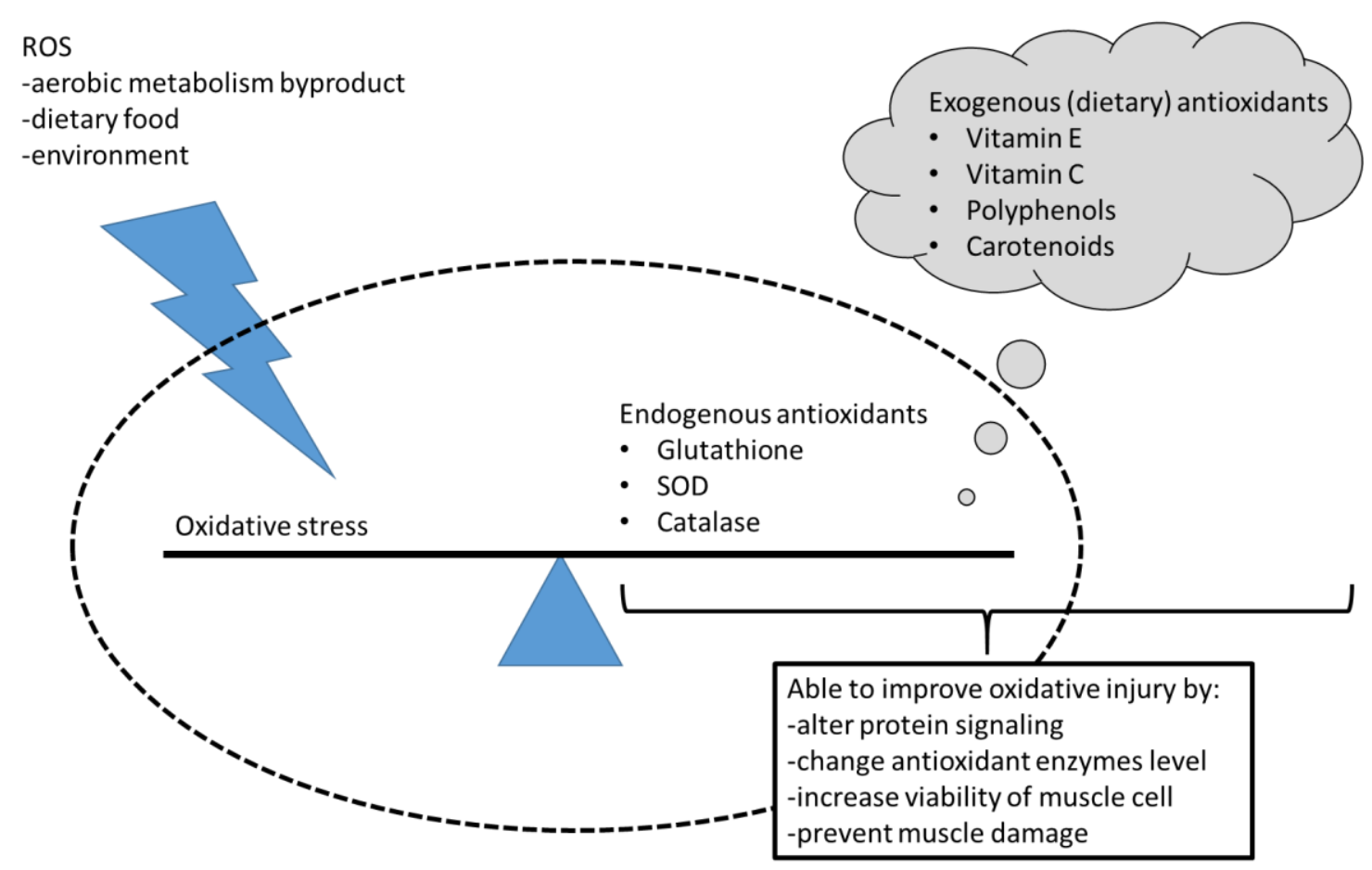

Fig.1: Illustration of the relationship between oxidants and antioxidants in maintaining the cellular redox balance. The dietary intake of exogenous antioxidants is suggested to improve the oxidative injury by several processes. 
Antioxidants specifically vitamins and other trace elements intake are necessary to allow endogenous adaption and minimize oxidative stress. Vitamin E was found to act as a non-enzymatic antioxidant to combat oxidative stress. The evaluation of antioxidant status particularly vitamin $\mathrm{E}$ is influence by the dietary intake and the endogenous antioxidants in the body itself. A strong correlation between plasma concentrations of antioxidants with physical performance and strength has been proposed. One of the vitamin $\mathrm{E}$ isomer, $\gamma$ tocopherol was demonstrated to enhance skeletal muscular strength (Cesari et al., 2004).

The other isomer, $\alpha$-tocopherol has shown its the ability to transfer its labile hydrogen to a lipid or lipid peroxyl radical and converts itself to the radical, which is then reduced back to its original form by ascorbic acid (Aslani, 2016). This might suggest the combination of vitamin $\mathrm{E}$ and ascorbic acid (vitamin C) will provide a stronger effect towards scavenging the ROS. It has been reported that exercise activity decreased plasma total antioxidant capacity (TAC) in rats, interestingly supplementation with tocotrienol-rich-fraction (TRF) showed an increase in the plasma TAC thus improved the endurance capacity (Lee et al., 2009).

On the other hand, a current finding showed that one of the vitamin $\mathrm{E}$ isomers, $\gamma$-tocotrienol inhibits TGF- $\beta 1$-induced expression of $\alpha$-smooth muscle actin ( $\alpha$-SMA) stress fibers, thus suggested $\gamma$ tocotrienol was able to reduce the generation of ROS in $\alpha$-smooth muscle cells (Fukushima et al., 2017). Muscle strength and physical performance in old age individual might be related to the oxidative damage caused by free radicals.

Tocotrienol-rich fraction (TRF) is a combination of isomers of vitamin $\mathrm{E}$ which is composed of tocotrienol and tocopherol. Previously TRF posttreatment was observed able to reverse the myoblasts aging though replenishing the regenerative capacity of the cells where with 50 $\mu \mathrm{g} / \mathrm{mL}$ TRF treatment against stress-induced premature aging model of myoblast exhibited the highest cell proliferation capacity (Lim et al.,
2013).It is well known that muscle cell integrity requires an adequate vitamin $\mathrm{E}$ ( $\alpha$-tocopherol) status. It has been proved that muscular force production in rats fed with vitamin E-deficient diet was lower compared to control supplemented vitamin $\mathrm{E}$ group.

Recent in vitro study shows that pre- and posttreatment with $\alpha$-tocopherol protected against $\mathrm{H}_{2} \mathrm{O}_{2}$-induced DNA damage of fibroblasts (Makpol et al., 2010).Additionally a study was conducted to investigate the effects between TRF and $\alpha$ tocopherolalone, which resulted in retrieving the young-like features and improved cell viability in senescent myoblasts. Interestingly, TRF exerted better effects than $\alpha$-tocopherol in promoting myoblasts proliferation at the MRNA and protein levels. The findings provide the initial benefits of the TRF that may contribute to future clinical translation, in which TRF can be potentially applied to improve the proliferation of muscle cells (Khor et al., 2016).In accordance with this, their latest published work, Khor et al. (2017)reported that TRF regulates the expression of antioxidant enzymes in three different stages of myoblasts (young, pre-senescent and senescent). Treatment with TRF in senescent myoblast resulted in diminished ROS and lipid peroxidation in addition to reinforcing the antioxidant defense system. This is in line with the another previous study, which is was reported that TRF is more potent than $\alpha$ tocopherol against oxidative damage in brain mitochondria (Kamat and Devasagayam, 1995)and more effective in inhibiting protein oxidation and lipid peroxidation in liver microsomes (Nesaretnam et al., 1993). This suggested that TRF is a potential antioxidant that can counteract oxidative stress and improve cellular survival during aging and potentially can be used to ameliorate muscle regeneration.

A study on animal shows that continuous supplementation of TRF for 8 months reduced DNA damage and exhibited positive influence in spatial learning of Wistar rats (Taridi et al., 2011).Many factors contribute to determine the effects of antioxidants supplementation on exercise 
performance, including; 1) the antioxidants delivered; 2) the antioxidant dose; 3) the type and intensity of the exercise performed (Powers et al., 2004).

The supplementation of vitamin $\mathrm{C}$ and $\alpha$-tocopherol to a group of $50-\mathrm{km}$ ultramarathon was able to prevent endurance exercise-induced lipid peroxidation but no apparent effect on inflammation (Mastaloudis et al., 2004). These findings suggest that oxidative damage cause by lipid peroxidation and the inflammatory response are operating independently (Nieman et al., 2002). Moreover, supplementation with antioxidant cocktail of vitamin $\mathrm{E}, \beta$-carotene and vitamin $\mathrm{C}$ on well-trained sportsmen enhances plasma antioxidants enzymes activity of superoxide dismutase (SOD) and catalase. Besides the SOD protein level was markedly higher in the supplemented group (Tauler et al., 2002). This findings suggested that vitamin $\mathrm{E}$ and other antioxidants supplementation not only improved the enzyme activity but also improve the protein level. In fact the result also suggested that one antioxidant cannot act alone to prevent oxidative damage. The combined action of multiple compounds derived from a diet rich fruits and vegetables cannot be replaced with a single antioxidant.

This may suggest that the beneficial effects of antioxidant specifically vitamin $\mathrm{E}$ on sport performance is influence by the types and intensity of physical activities as well as the different duration and concentration/dose of vitamin $\mathrm{E}$ consumed by the athletes. It is also reasonably clear that not all isomers of vitamin $\mathrm{E}$ have the same physiological and metabolic effects.

\section{Animal study}

Animal study by Lee et al. (2009) reported that tocotrienol-rich-fraction (TRF)-treated rats with different doses $(25 \mathrm{mg} / \mathrm{kg} / \mathrm{ml} \mathrm{TRF}$ and $50 \mathrm{mg} / \mathrm{kg} / \mathrm{ml})$ increase the exercise endurance by improving the swimming time compared to $\alpha$-tocopherol treated group. Besides TRF-treated group for both doses show higher concentrations of antioxidants enzymes such as SOD, catalase and glutathione peroxidase.Thus, this suggests that TRF have a potential effect to improve physiological condition thus increase physical performance compared to tocopherol.

Moreover, a recent animal study done by Betik et al. (2016),shows that the 10 weeks supplementation of vitamin $\mathrm{E}$ tocotrienols (TCTs)improves the endurance exercise capacity in high-fat diet fed rats. By using the treadmill-test to exhaustion, the treated group with TCTs was able to run significantly further that the untreated group (2271 $\pm 185 \mathrm{~m} ; 1428 \pm 139 \mathrm{~m})$, respectively. Besides the researchers also found that treatment with TCTs influence the post-exercise plasma glucose level. This novel finding provides new awareness of the potential nutrient to increase exercise tolerance in populations at-risk of developing obesity which in turn could aid in the prevention of insulin deficiency-associated diseases.

\section{Vitamin E supplementation: no effects on sport performance?}

High levels of ROS produced in skeletal muscle during exercise have been associated with muscle damage and impaired muscle function. A review by Peternelj and Coombes (2011), summarized in certain condition cell loading with high doses of antioxidants leads to a blunting of the positive effects of exercise training and interferes with important ROS-mediated physiological processes. Indeed, although ROS are associated with harmful biological events, they are also essential to the adaption of optimal development of each cell.

Furthermore, hypoxia exposure is able to boost up the production of ROS. An intense normoxic training associated with resting exposures to hypoxia during a long period (18 days) worsened the antioxidant capacities of the runners (Pialoux et al., 2009).There has been some disagreement concerning the negative effects of vitamin $\mathrm{E}$ in the physical performance, where various approaches showed some contradictory results. Although tocotrienol-rich palm vitamin $\mathrm{E}$ supplementation 
decreased lipid peroxidation at rest of the male recreational athletes, but in some extent during exercise in the heat, it did not enhance endurance running performance or prevent exercise-induced muscle damage (Keong et al.,2006).

A previous study has indicated that vitamin $\mathrm{E}$ reduced the magnitude of contraction-induced lipid peroxidation in the rats tibialis anteriormuscle, however no improvement has been observed in the fatigues resistance on this muscle (Coombes et al., 2001). This may suggest that high doses of vitamin $\mathrm{E}$ has a negative effect on skeletal muscle function. Nonetheless, whether or not dietary supplementation with high doses of vitamin $\mathrm{E}$ would give beneficial effects and impair human muscle performance is still remain unclear.

A recent clinical trial shows that supplementation of vitamin $\mathrm{C}$ and $\mathrm{E}$ on muscle damage and oxidative stress have no significant effect specifically in women athlete (Taghiyar et al., 2013). This could be due to different types of exercise, the level of intensity as well as the dose consumed.

This is supported by Bjørnsen et al. (2016), which implemented vitamin $\mathrm{E}$ and $\mathrm{C}$ supplementation with 34elderly males aged $60-81$, the population was either placed in a supplementation group $(500 \mathrm{mg}$ vitamin $\mathrm{C}$ and $117.50 \mathrm{mg}$ vitamin $\mathrm{E}$ before and after training) or a placebo group. The results showed that vitamin $\mathrm{C}$ and $\mathrm{E}$ supplementation blunts increase in total lean body mass in elderly men after strength training, revealing a larger lean mass gains in the placebo group. Similarly, the thickness of rectus femoris muscle increased more in the placebo group than in the antioxidant supplemented group.

The contradiction findings may be resulted from several factors includes the strength gains might be due to the different training intensity of the subjects and due to the two vitamins being taken in combination. Taken together, further study must be done to elucidate the effects of the vitamins $\mathrm{C}$ and $\mathrm{E}$ alone and combination with various doses. Apart from this, no improvement effect was found after 6-weeks supplementation with tocotrienol-rich palm vitamin $\mathrm{E}$ in endurance running performance in heat-adapted recreational athletes. The researchers proposed the reason of the lack of the positive effects may be caused by the recruited subjects of the study had adequate vitamin E stores, therefore additional supplementation did not bring any extra benefits to them (Keong et al., 2006). Moreover it is possible potential benefits may only be observed in vitamin $\mathrm{E}$ deficient individual. Besides, the duration of the supplementation also may influence the result, as previously study by Rokitzki et al. (1994), where the $\alpha$-tocopherol was supplemented for a prolong period of 5months to cyclists.

\section{Conclusion}

Over the past 10 years, there has been increasing attention on the importance of antioxidants specifically vitamin as the important micronutrient to maintain and improve physical performance specifically towards the muscle cells. Muscle cells contain a complex cellular defense mechanism to prevent and minimize the risk of oxidative injury. The endogenous and exogenous antioxidants are the major important network that protect the cell against oxidative stress.

A study on rats which had been fed with vitamin $\mathrm{E}$ deficient diet showed the impairs muscular endurance and alters muscle contractile properties following a prolonged series of contractions (Coombes et al., 2002). Although some animal studies and in vitro test have demonstrated the potential effects of vitamin $\mathrm{E}$ in improve muscular performance, to date there is still limited evidence that dietary supplementation with vitamin $\mathrm{E}$ will improve the individual performance specifically the athletes.

A research which involves the athletes still remain unclear and invalidated as it may influenced by their personal opinions, specifically in sport studies, the majority of athletes and well-trained 
individuals do not feel comfortable discussing this issues with researchers. They might lie or might not clearly express their opinions despite confidentiality guarantees. A recent findings revealed that $20 \%$ of the well-trained participants competed in endurance modalities (cycling or middle- or long distance running) was lied in the exclusion criteria of antioxidant supplementation in a personal interview, as they showed a high alpha-tocopherol concentration in plasma after high performance liquid chromatography (HPLC) verification of their blood (Barranco-Ruiz et al., 2017). On the other hand, some of the studies were using low sample size and recruited less subjects, thus contribute to poor analysis of the results. In fact, a diverse range of participants with larger samples and validated instruments used are plays important role to ensure the accuracy and validity of the obtained results.

Antioxidants effects seem to give influences from the different ages of the subjects or athletes. This is in line with a study on evaluation of the effects of functional beverages based on almonds and olive oil and enriched with $\alpha$-tocopherol and docosahexaenoic (DHA) on physical performance in sportsmen, which has been reported able to enhance the gene expression of antioxidant enzyme after exercise in young athletes but not in senior athletes (Capóet al., 2016). Taking into account that oxidative damage is one of the precursor of aging process that may cause from various cellular damage and in the case of excessive stress, cellular death will occur either by apoptosis of necrosis.

An increasing evidence has shown the potential of vitamin $\mathrm{E}$ in preventing programmed cell death or apoptosis process. A study by Makpol et al.(2012), was observed that $\gamma$-tocotrienol inhibited cytochrome c release and decreased activation of caspase- 9 and caspase- 3 and down regulated the gene expression of BAX, up-regulated BCL2A1 and decreased the ratio of $\mathrm{Bax} / \mathrm{Bcl}-2$ protein expression in aging model. These findings suggested that $\gamma$-tocotrienol inhibits apoptosis by modulating the upstream apoptosis cascade, causing the inhibition of cytochrome $\mathrm{c}$ release from the mitochondria with concomitant suppression of caspase- 9 and caspase- 3 activation.

As review by Pingitore et al. (2015), the protective effect of a diet containing natural sources of antioxidants is probably not equivalent to the protective effect of supplementation. A diet rich in antioxidants may really be a non-pharmacologic and natural ways to maintain a physiological antioxidants status. Based on the conflicting evidence on the effects of combination of vitamin $C$ and vitamin $\mathrm{E}$, a prolong or continuous intake of the non-physiological dosages of the vitamins should not be recommended to healthy individual.

Collectively, it becomes challenging to draw a clear conclusions the effects of vitamin $\mathrm{E}$ on the physical performance specifically in sportsmen. Too many differences exist among the studies in term of types of exercise (aerobic or anaerobic), types of tissues (blood or cells), age of the subjects (young or old) and last but not least the training endpoints examined. Besides, a good research design and selection of valid and reliable biomarkers also plays as important role in order to obtain an accurate result.

The interrelationship of exercise, oxidative stress and vitamin E supplementation remains extremely complex, which they are depending on the mode, intensity and duration of the exercise and individual susceptibility to oxidative stress injury determined by genetic and lifestyle factors. Although much work of the potential of vitamin $\mathrm{E}$ on the physical performance has been carried out, to date there is still poor evidence that dietary supplementation with vitamin $\mathrm{E}$ will improve sport performance. Further investigation need to be carried out to reveal the benefits of vitamin E. Taken together, it can be suggested that antioxidants supplementation rich in vitamin E may act as alternative strategy to improve physical performance.

\section{Conflict of interest statement}

Authors declare that they have no conflict of interest. 


\section{References}

Adams, A.K., Best T.M. 2002. The role of antioxidant in exercise and exercise and disease prevention. Phys. Sport.30, 37-44.

Asha D.S., Prathima S. S. M. 2003. Dietary vitamin $\mathrm{E}$ and physical exercise: I. Altered endurance capacity and plasma lipid profile in ageing rats. Exp. Gerontol. 38, 286-290

Aslani, B.A. 2016. Studies on oxidants and antioxidants with a brief glance at their relevance to the immune system. Life Sci.146, 163-173.

Barranco-Ruiz, Y., Aragon-Vela, J., Casals, C., Martinez-Amat, A., Casuso, R.A., Huertas, J.R. 2017. Control of antioxidant supplementation through interview is not appropriate in oxidative-stress sport studies: Analytical confirmation should be required. Nutr33, 278284.

Betik, A. C., Aguila, J., McConell, G. K., McAinch, A. J., Mathai, M. L. 2016. Tocotrienols and whey protein isolates substantially increase exercise endurance capacity in diet -induced obese male Sprague-Dawley rats. PLoS One11, e0152562.

Bjørnsen, T., Salvesen, S., Berntsen, S., Hetlelid, K.J., Stea, T.H., Lohne-Seiler, H., Rohde, G., Haraldstad, K., et al. 2016. Vitamin C and E supplementation blunts increases in total lean body mass in elderly men after strength training. Scand J Med Sci Sports, 26(7), 755.

Capó, X., M. Martorell, C. Busquets-Cortés, A. Sureda, J. Riera, F. Drobnic, J. A. T., A. P. 2016. Effects of dietary almond- and olive oilbased docosahexaenoic acid- and vitamin Eenriched beverage supplementation on athletic performance and oxidative stress markers. Food Funct.7, 4920-4934.

Cesari, M., Pahor, M., Bartali,B., Cherubini, A., Brenda, W.J.H, Penninx, G., Williams, R., Atkinson, H., Martin, A., Jack, M.G. 2004. Antioxidants and physical performance in elderly persons: the Invecchiare in Chianti (InCHIANTI) study1,2,3. Am J Clin Nutr79, 289-294.

Coombes, J.S., Powers, S.K., Rowell, B., Hamilton,
K.L., Dodd, S.L., R., Shanely, A., Sen, S.K. 2001. Effects of vitamin $E$ and $\alpha$-lipoic acid on skeletal muscle contractile properties. Journal of Applied Physiology, 90(4), 1424-1430.

Coombes, J.S., Rowell, B., Dodd, S.L., Demirel, H.A., Naito, H., Shanely, R.A., Powers, S.K. 2002. Effects of vitamin $E$ deficiency on fatigue and muscle contractile properties. Eur J Appl Physiol. 87, 272-277.

Fukushima, T., Yamasaki, A., Harada T., Chikumi, H., Watanabe, M., et al. 2017. $\gamma$-Tocotrienol Inhibits TGF- $\beta 1$-Induced Contractile Phenotype Expression of Human Airway Smooth Muscle Cells. Yonago Acta. Med.60, 16-23.

Gomez-Cabrera, M.C. et al. 2006. Oxidative stress in marathon runners: interest of antioxidant supplementation. Br. J. Nutr.96, S31-S33.

Halliwell, B., Gutteridge, J. M. C. 1999. Free radicals in biology and medicine. New York: Oxford Univ. Press.

Kamat, J.P., Dewasagayam, T. 1995. Tocotrienols from palm oil as potent inhibitors of lipid peroxidation and protein oxidation in rat brain mitochondria. Neurosci Lett, 195(3), 179-82.

Keong, C.C., Singh, H.J., Singh, R. 2006. Effects of palm vitamin $\mathrm{E}$ supplementation on exerciseinduced oxidative stress and endurance performance in the heat. J Sports Sci Med. 5(4), 629-639.

Khor, S.C., Razak, A.M., Ngah, W.Z.W., Yusof, Y.A.M., Karim, N.A., Makpol, S. 2016. the tocotrienol-rich fraction is superior to tocopherol in promoting myogenic differentiation in the prevention of replicative senescence of myoblasts. PLoS One, 11(2), e0149265.

Khor, S. C., Wan Ngah, W. Z., Mohd Yusof, Y. A., Abdul Karim, N., Makpol, S. 2017. Tocotrienol-Rich Fraction Ameliorates Antioxidant Defense Mechanisms and Improves Replicative Senescence-Associated Oxidative Stress in Human Myoblasts. Ox. Med. Cell. Longevity.

https://doi.org/10.1155/2017/3868305

Lee, S. P., Mar, G. Y., Ng, L. T. 2009. Effects of tocotrienol-rich fraction on exercise endurance capacity and oxidative stress in forced 
swimming rats. Europ. J.of App.Physio, 107(5), 587-595

Lim, J. J., Ngah, W. W. Z., Mouly, V., Abdul Karim, N. 2013. Reversal of myoblast aging by tocotrienol rich fraction posttreatment. Ox. Med. Cell. Longevity, https://doi.org/10.1155/2013/978101

Makpol, S., Zainuddin, A., Rahim, N.A., Yusof, Y.A. 2010. Alpha-tocopherol modulates hydrogen peroxide-induced DNA damage and telomere shortening of human skin fibroblasts derived from differently aged individuals. Planta Med, 76(9), 869-75.

Makpol, S., Rahim, N.A., Hui, C.K., Ngah, W. Z. W. 2012. Inhibition of Mitochondrial Cytochrome c Release and Suppression of Caspases by Gamma-Tocotrienol Prevent Apoptosis and Delay Aging in Stress-Induced Premature Senescence of Skin Fibroblasts. Oxidative Medicine and Cellular Longevity, Article ID.785743.

Mastaloudis, A., Morrow, J.D., Hopkins, D.W., Devaraj, S., Traber, M.G. 2004. Antioxidants supplementation prevents exercise-induce lipid peroxidation, but not inflammation, in ultramarathon runners. Free Rad Biol Med. 36(10), 1329-1341.

Nesaretnam, K., Devasagayam, T.P., Singh, B.B. 1993. Influence of palm oil or its tocotrienolrich fraction on the lipid peroxidation potential of rat liver mitochondria and microsomes. Biochem Mol Biol Int, 30(1), 159-67.

Nieman, D.C., HEnson, D.A., McAnulty, S.R., McAnulty, L., Swick, N.S., Utter, A.C., Vinci, D.M., Opilela, S.J., Morrow, J. D. 2002. Influence of vitamin $\mathrm{C}$ supplementation on oxidative and immune changes after an ultramarathon. J Appl. Physiol. 92, 1970-1977.

Peternelj, T.T., Coombes, J.S. 2011. Antioxidant supplementation during exercise training: beneficial or detrimental? Sports Med, 41(12), 1043-69.

Pialoux, V., Mounier, R., Rock, E., Mazur, A., Schmitt, L., Richalet, J-P., Robach, P., Brugniaux, J., Coudert, J., Fellman, N. 2009. Effects of the 'live high-train low' methid on prooxidant / antioxidant balance on elite athletes. Europe J Clin Nutr. 63, 756-762.

Pingitore, A., Lima, G. P. P., Mastorci, F., Quinones, A., Iervasi, G., Vassalle, C. 2015. Exercise and oxidative stress: Potential effects of antioxidant dietary strategies in sports. Nutrition, 31(7-8), 916-922.

Powers, S. K., Deruisseau, K. C., Quindry, J., Hamilton, K. L. 2004. Dietary antioxidants and exercise. J Sports Sci, 22(1), 81-94.

Ratnam, D.V., Ankola, D.D., Bhardwaj, V., Sahana, D.K., Ravi Kumar, M.N.V. 2006. Role of antioxidants in prophylaxis and therapy: A pharmaceutical perspective. J Controlled Release, 113(3), 189-207.

Rokitzki, L., Logemann, E., Huber, G., Keck, E., Keul, J. 1994. Alpha-tocopherol supplementation in racing cyclists during extreme endurance training. Int J Sports Nutr.4, 253-264.

Sakellariou, G.K., Jackson, M. J. 2014. Redefining the major contributors to superoxide production in contracting skeletal muscle: the role of NAD(P)H oxidases. Free Rad Res., 48(1), 1229.

Sarir, H., Emdadifard, G., Farhangfar, H. 2015. Effect of vitamin E succinate on inflammatory cytokines induced by high-intensity interval training. J Res Med Sci, 20(12), 1177-1181.

Sen, S.K. 2001. Antioxidants in exercise nutrition. Sports Med, 31, 891-908.

Taghiyar, M., Darvishi, L., Askari, G,. Feizi, A., Hariri, M., Mashadi, N.S., Ghiasvand, R. 2013 The effect of vitamin $\mathrm{C}$ and e supplementation on muscle damage and oxidative stress in female athletes: A clinical trial. Int $\mathbf{J}$ Prev Med4, 16-23.

Taridi, N.M., Yahaya, M.F., Teoh, S.L., Latiff, A.A., Ngah, W.Z.W. Das, S. M. M. 2011. Tocotrienol rich fraction (TRF) supplementation protects against oxidative DNA damage and improves cognitive functions in Wistar rats. La Clinica Terapeutica, 162(2).

Tauler, P., Aguiló, A., Fuentespina, E., Tur, J., Pons, A. 2002. Diet supplementation with vitamin $\mathrm{E}$, vitamin $\mathrm{C}$ and $\beta$-carotene cocktail enhances basal neutrophil antioxidant enzymes in athletes. Pflữgers Archiv Eur. J. Physiol.443, 
791-797.

Valko, M., Leibfritz, D., Moncol, J., Cronin, M.T.,

Mazur, M., Telser, J. 2007. Free radicals and antioxidants in normal physiological function and human diseases. Int. J Biochem Cell Biol. 39, 44-84.

\section{How to cite this article:}

Abdul Rahim. N., Mohamad Shalan, N. A. A., 2018. The potential effects of vitamin E in sport performance. Int. J. Curr. Res. Biosci. Plant Biol. 5(12), 17-27.

doi: https://doi.org/10.20546/ijcrbp.2018.512.003 